Inmaculada Fortanet, Juan Carlos Palmer \&

Santiago Posteguillo*

\title{
The Emergence of a New Genre: Advertising on the Internet (netvertising)
}

\begin{abstract}
This article describes the specific characteristics of internet genres. These genres are characterized by the net system, a specific interlanguage, hypertext, the multimedia effect and an interactive audience. Netvertising is analysed as a representative example of an internet genre. A set of 20 first web pages of banner ads has been studied. The parameters considered are the following ones: http linkers, images used, integration of visuals with text, objectives of the ad, register, audience, overall page length, sentence length, verb tenses, punctuation marks and personal pronouns. Results show that most net ads are short texts. This conciseness is offset by a wider use of other devices such as punctuation marks, images and http linkers. Banner ads are based on an elaboration of images, with the text used, mainly a variety of brief sentences and noun phrases.
\end{abstract}

\section{Introduction}

A traditional old conception of the term genre stemming from early Aristotelian perspective postulated the view of genres as static structures mainly valuable for classificatory and explanatory purposes of basically literary manifestations. Linguists, as Levinson (1979) noted, were reluctant to incorporate an originally artistic term in their investigations - especially when such inclusion would collide with much more linguistically established concepts such as those of discourse or register ${ }^{1}$. Additionally, collateral research work in such areas as folk-

1 For further explanations on the conflict between genre, discourse, and register, see Frow (1980), Ventola (1984), Martin (1985) and Couture (1986).

* Inmaculada Fortanet, Juan Carlos Palmer \& Santiago Posteguillo Universitat Jaume I

Castello 
lore studies contributed to the idea of genres as static instances that were preserved and transmitted through tradition and cultural environment (Ben-Amos 1976) in such instances as myths, legends or tales. This tendency condemned the term to an enslaved existence in the world of taxonomies.

A relatively new linguistic trend has come to re-define genre, adding to the concept not just form or structure, but also content, situation, context and objectives or communicative purposes (Swales 1990, Bhatia 1993, Devitt 1993, Berkenkotter and Huckin 1995). All these items become as central to the new conception of genre as form and if one of them is modified this, in turn, implies a modification of the genre as a whole ${ }^{2}$ - and situations, contexts and objectives vary according to the natural evolution of the discourse communities in which genres are realized. Consequently, genres change, being not static but dynamic instances subject to transformation.

Bitzer (1968) spoke of the existence of recurrent rhetorical situations and Schutz and Luckmann (1973) claimed that rhetorical instances underwent a process of systematic typification. Miller (1984) then extended the relevance of the concept of recurrence from the traditional literary and/or academic genres studied by linguistic insight to the rhetorical instances of everyday life (greetings, expressions of love or disgust, informal notes and similar natural daily generic instantiations). In an interesting metaphor, Berkenkotter and Huckin (1995) considered this as enhancing the traditional linguistic analysis which focused on the genres of the senate to the incorporation of the genres of the agora as well. In this paper, we are concerned with the recurrent rhetorical instances which are taking place and undergoing a systematic process of still unstable typification in the specific context of the Internet. An initial research question may then be "is Internet a senate or an agora?" Our assumption, and one of the ideas for which we endeavor to disclose some empirical proofs is that, even though the Internet was initially designed as a form of elitist academic senate (after its original military objectives), it has now radically turned into an agora undoubtedly the widest and most international agora ever in human history. A drastic change was brought about in the mid 90s when, along with an enormous - almost uncontrolled - expansion of the network,

2 For the idea of genre integrity see Bhatia (1994). 
the commercial possibilities in both economic exchange and advertising of products have completely altered the initial concept of an $a c a$ demic Internet. This transformation has had a rippling effect in the way genres - originally designed for a different context and situation - are being reproduced on the net.

How are we to approach the study of these unstable generic forms in constant rapid evolution? This poses an additional problem. Bakhtin (1986) distinguished between primary genres and secondary genres. The first group referred to those genres which are part of our daily experience (greetings, etc...), being simple and immediate in their instantiation and the feedback they create. In contrast, secondary genres involve those which "are removed from their instantiation"; in other words, those genres whose feedback is not immediate but distant - this is the case of, for instance, research articles in academic journals. This distance between instantiation and response makes these genres far more complex discursive manifestations of human thought. In relation to this division of genres, Internet genres represent a mixture of both primary and secondary Bakhtinian genres: many of these Internet genres stem from originally complex secondary well-established and developed secondary genres - such as research articles - but the immediacy of the receiver's response is highly increased, bringing these new textual forms closer to the nature of primary genres; this is especially the case of e-mail messages or participatory genres which are now in vogue on the net (newsgroups, etc...). Ferrara, Brunner and Whittemore (1991) maintain that technology alters genres, producing what they define as blurred genres, and Yates and Orlikowski (1992) study and describe how a specific technological advancement resulted in a parallel generic revolution: this was the case of the appearance of the typewriter which favored a substantial increase of correspondence among businesses on the one hand and, at the same time, contributed to the standardization of formats, styles and contents of these letters on the other. Among the various changes, Yates and Orlikowski also include the appearance of a new profession - typists - who, for a substantial period of time, had an influence on the evolution of these genres. Nowadays, typing has become a necessary skill for office workers - although it is now usually in demand in combination with word-processing. 
Similarly, it is our contention that the appearance of Internet is creating a set of new generic forms for which we are yet to see which will prevail and which will simply be a flash in the pan. For instance, will html language become another necessary skill for professionals in such fields as advertising? Or will html and web pages create a new profession altogether?

Another important question is how far this generic evolution can advance. Berkenkotter and Huckin (1995) stress the significance of both form and content in the definition of genres. For them form and content influence the development of a genre in various ways: epistemologically, depending on the audience's background knowledge, depending on the newness of the genre and depending on the kairos or "rhetorical timing". The wider the background knowledge of a discourse community is in relation to an emerging genre, the more that genre may evolve and depart from its original forms and contents. Additionally, the appropriate kairos or rhetorical timing is also essential and it seems very likely that the situation and audience is ripe for a substantial advancement in new generic forms as they are being developed in Internet - see Adell's (1994) preliminary descriptions of new genres which he is able to outline as already existing on the net only a couple of years later (Adell 1996).

Finally, among the new emerging genres on the Internet, advertising - in its various forms - represents one of the leading discursive manifestations of this process of continuous generic change which is currently taking place in this international computing agora. The significance of advertising in relation to sociolinguistic analysis has already been addressed regarding its more traditional forms of television, newspaper, magazine and other advertising media (Myers 1994). We have focused on the sociodiscursive study of target ads (linked to banner ads) - the most extended form of netvertising - as a representative genre of the new trend of textual manifestations which are to be encountered in the ever growing world of the Internet.

\section{Characteristics of Internet genres}

According to the definition of genre, there should be a group of features that define a certain kind of discourse as a separate genre. 
Internet is a new means of communication which has become popular only in recent years. Much of what can be found on it is not systematized yet. This new means of communication has led to new genres, such as the web page or huge multimedia catalogues, but also to the application of existing ones, such as advertising or research articles. There are several features that all these genres have in common, among which we would like to highlight a few.

\subsection{The net system}

In all the previous communication systems, speech was defined as what a speaker transmitted to a hearer. Consequently, both speaker and hearer had an important role in the communication process. The Internet has completely changed this generally assumed proposition. The issuer of the communication has very often lost his/her identity (for example, in an e-mail message the only thing you know about the issuer of the message is a codified "address"), and messages can be addressed to just one person, but on most occasions, they can be reached by anybody, any person in the whole world (for example, advertisements). No other means of communication has ever had such a wide audience. Consequently, since the message is the essence of the communication, only the message is important.

\subsection{Interlanguage}

In relation to what we have just said, if a message comes from anybo$\mathrm{dy}$ in the world, and is addressed to anybody else, what is the consequence in the language used? We can say that over $90 \%$ of the information you can find on the Internet is in English. As is well-known, nowadays English is the most international language in the world. The use of any other language means a positive action towards the restriction of the audience.

But the English language may be greatly altered if the use of Internet continues expanding. Most Internet users are non-native speakers or even exclusively writers - of English, who do not use this language in their daily life, which means they are suffering continuous interference from their various mother tongues.

Additionally, there is the special metalanguage that this new means of communication is producing, with expressions such as the follow- 
ing: to link (relate different parts of a document by means of hypertext), cookie (some kind of file that stores information), communicon (= communication + icon; combination of letters and symbols used on the Internet e-mail to provide emphasis or clarification (Ellsworth et al. 1997: 395-412)), and similar expressions.

What will be the result of using English as the international net language? This is an open problem that future sociolinguistic research will have to deal with.

\subsection{Hypertext}

One special characteristic of Internet is the use of hypertext; this means that the information is distributed in layers to which the reader can have access just by choosing a word or icon and double clicking on it. In this way, readers of the same text may get different readings from it, depending on the layers of information they have opened and the order in which they have done it.

\subsection{Multimedia effect}

On the Internet, you do not only find texts. Other communication elements are interlinked with the "traditional computer texts", such as movies and animation, moving graphics, sound files, databases and catalogues, and programs that run directly on your computer (Ellsworth et al. 1997: 4-5). Day after day new technologies appear, allowing computing designers to introduce new elements (Ellsworth et al. 1997: 26), as for example:

1. Java - which provides for some mini-applications or programs for motion, sound, calculation, and other functions;

2. Shockwave, which allows multimedia movies to be embedded;

3. RealAudio, which provides sound in real time or via files.

\subsection{The role of the audience}

The most evident innovation that this new means of communication has brought is the change in the role of the audience. From now on, receivers will not be passive any more; they have to take decisions and act, if they want to receive the message. Moreover, they can choose the message they want to receive as well as when and how to read it. They can 
also decide if they want to respond to the message or not, and also when and how to do it. Of course, not all information is transmitted in the same way on the Internet, but this will be a recurrent characteristic of the communication process within the World Wide Web.

All these characteristics make the Internet a new and peculiar means of communication which, as we said above, is leading to the creation of new genres and to new applications of traditional ones. These new genres and applications will deserve the special attention of linguistic researchers. In our case, we would like to give an example of how to analyze netvertising - that is, advertising on the Internet.

\section{Netvertising: the emergence of a new genre}

The language of advertising, together with the effectiveness of advertising as a marketing strategy, has been widely analyzed. However, these analyses have not yet been applied to the Internet advertising, or netvertising.

Before starting the analysis of Internet advertisements, or netads, we have made a bibliographical search to first define what is advertising, different kinds of advertising, and the parameters traditionally analyzed in the language of advertising.

We can say that advertising is informing the public or a sector of the public about a product, company, service, action, etc. The language used is usually selected with great care to meet particular aims. Apart from informing, advertisements are also used to persuade and influence (Vestergaard and Schröder 1985: vii). There are two main kinds of advertising, according to Vestergaard and Schröder (1985: 1-3): noncommercial and commercial advertising. The former includes communications from government agencies to citizens, and appeals from various associations and societies, with aims that range from charity to political propaganda. Commercial advertising can take many forms; for example it can be used to advertise the name or image of a company by means of public extracts of company reports or accounts in prestigious newspapers (prestige advertising). Another type of commercial advertising is industrial advertising in which a firm advertises its products or services to other firms. This type of advertising is different from prestige and consumer advertising, because both the advertiser and the prospective reader have a special interest in what is being advertised, and 
they have some knowledge about it. This is reflected in the language used; factual information is more important and there is less emphasis on persuasion. The third type is consumer advertising, in which a firm tries to sell its products or services to the consumers.

All these kinds of advertising are used on the Internet: prestige and industrial advertising can be found in specific http addresses, which interested users may find specifically for each occasion. We are more concerned with consumer advertising which, as we shall see, is very frequent on the net.

Next, we have looked into the different parameters traditionally analyzed for advertising. The first source we have considered is the book by Vestergaard and Schröder, The Language of Advertising (1985: 1348), which distinguishes between two kinds of parameters: the verbal message and the visual message. In the verbal message, they study the communication situation; textual structure: cohesion and coherence; information structure; content: implicit and explicit; and participant roles. Related to the visual message, they study text and picture; images and communication; icon, index, and symbol; denotation and connotation; and visual emphasis.

Our second source has been the book edited by Myers, Words in Ads (1994), in which the following parameters for advertising research are dealt with: slogans; sentence type and sentence structure; puns, associations and meanings; pronouns and addresses; languages and varieties as signs; conversations and everyday life; metaphor; words and pictures; and audiences.

Finally, our third source for reference is the book by Berke, Successful Advertising for Small Businesses (1996). This is, as its subtitle explains "a complete guide to planning, writing, designing and laying out great advertising". It is not a research monograph but it includes some advice on how to write advertisements, paying attention to the following aspects: headlines; length; and pictures and captions.

All these parameters have not been established for any means of communication in particular, though it seems obvious that the importance of the image is greater in a television commercial than in a newspaper advert. The question that remains unanswered is if all these parameters are applicable to netvertising. This will be one of the aims of this study: to establish parameters that can be studied in a corpus of netadverts. 


\subsection{Method}

For this study we will use a corpus of 20 first web pages of 'target ads'. Novak and Hoffman (1996: 4) define a 'banner ad' as "a small, typically rectangular, graphic image which is linked to a target ad.(...) Banner ads typically provide little information other than the identification of the sponsor, and serve as an invitation for the visitor to click on the banner to learn more". Banner ads, according to Chatterjee (1996), are a form of passive advertising exposure. Once the reader/ consumer decides to click on the banner ad, and so gaining access to the target ad, $\mathrm{s} / \mathrm{he}$ is exposed to active advertising. We decided to choose first pages of target ads for our study because banner ads have little language material to be analyzed, and there is usually a very complex and constant change of text and image in motion, which makes an analysis very difficult.

Additionally, we decided to limit the corpus to first pages because some ads have a very large number of linkers that lead the viewer to a never ending process of selecting paths to get more and more information. On the other hand, another criterion followed in the choice of the corpus was the selection of only those adverts whose first pages had enough text and content to be analyzed, since some of these first pages were just indexes or tables of contents with lists of items to choose from.

As for the parameters, we decided that it would be interesting to observe the different elements of content (http linkers, different types of images used - pictures, photographs, cartoons... -, integration of these elements, etc.) that could be found in each advert. We thought this parameter could be rather different from those used for traditional advertising. After a thorough examination, we chose the linkers and the images for our analysis, paying special attention to their relationship with the text.

Other parameters we have analyzed are:

- Objectives of the advertisements

- Register and audience

- Linguistic analysis: overall page length of the advertisements, sentence length, tenses, punctuation marks and personal pronouns.

Our hypothesis is that we can obtain new and different results in this corpus, in comparison with other genres where we have already ana- 
lyzed some of these variables. ${ }^{3}$ This is but a short list of the parameters that can be analyzed with a corpus of netadverts. Many of those proposed by the authors mentioned before could also be studied, and it would be very interesting to compare the results with those obtained with a corpus of other kinds of advertisements.

However, the aim of the present research was not to obtain final results that could lead us to important conclusions on netvertising. We just wanted to introduce a new genre and new ways to study it. The main difficulty of such work is that nothing has been done before: there are neither taxonomies to be applied, nor results to compare with; everything has to be done from scratch.

In the next section, we will present the results we have obtained after analyzing the parameters mentioned before, and the taxonomies we propose for this and further research.

\section{Analysis and discussion}

\subsection{Objectives of the advertisement}

Certainly all advertisements aim at selling the products they advertise; however there are variations in the directness of this final objective due to different advertising strategies. Thus, we could say that some advertisements focus more on influencing or trying to change their consumers' attitudes towards a certain product, whereas others are more direct and straightforward in their approach to their audience. Additionally, in the context of the Internet, advertisers could take advantage of this advanced technological environment and obtain information from their potential buyers. Taking into consideration these different approaches to advertising, we have noticed that in the corpus of 20 netads selected, 16 aimed at changing the audience's opinions, 11 included elements of direct sale of a product, but only 5 took advantage of the technological possibility of the net to obtain information from potential buyers. Whether this lack of full exploitation of all the capabilities of the new context in which these ads are being exhibited (i.e. the Internet) is due to a deliberate advertising strategy - i.e. advertisers may regard the re-

3 See Fortanet et al. (1996), Posteguillo (1996), Palmer and Posteguillo (1997a), and Fortanet et al. (1997) for linguistic analyses of the use of tenses, use of punctuation marks, sentence length, and other similar linguistic variables. 
quest of information from the buyer as a negative approach - or simply a matter of a not yet complete adaptation of the genre of advertising to a new technological context remains as an open question with relevant sociolinguistic implications for further future research.

\subsection{Register and audience}

In relation to the register of these netads, and paying special attention to vocabulary and style, we distinguish between three different levels: a colloquial, neutral and technical register. A predominance of the colloquial register has been detected - with 10 ads at this colloquial level and 5 with a combination of a colloquial and a neutral register; 3 appeared written in a neutral level and only 2 incorporated a technical style.

\subsection{Linguistic analysis}

After analyzing this type of advertisements, we observed that most of them were fairly short, ranging from one to three pages. In fact, out of the 20 ads analyzed, 12 of them were just one page long, 2 of them could be printed in a couple of pages, whereas the other 6 were printed in three pages. It seems as if the first feature that we could see in our analysis was conciseness.

In fact, our second analysis showed that the number of sentences and noun phrases appearing in the twenty ads was an average of 40.4 statements per advert. ${ }^{4}$ Considering this number, we can conclude that there are definitely more statements than in traditional press ads. Therefore, it is important to observe how long those statements are.

Also in the study of statement length, we could observe the characteristic of conciseness. In fact our data showed that, among the 20 ads observed, a huge percentage of statements were either one or two words long. Only a few sentences were formed by 20 or more words, which seemed to prove that conciseness, being one of the most important qualities of advertising, becomes even more important when dealing with netvertising. Figure 1 shows this trend.

4 The total figure observed after analysing the twenty ads was 808 sentences or noun phrases. 


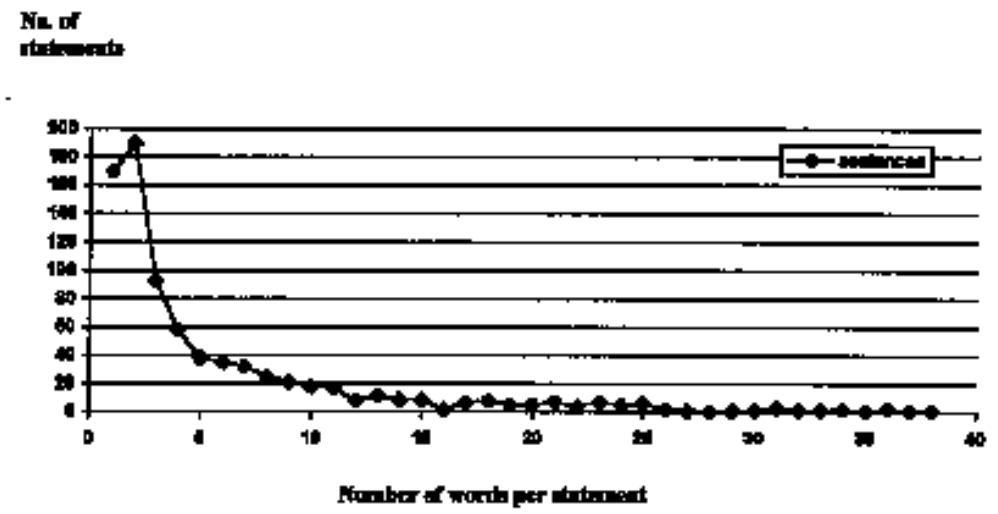

Figure 1. Statement length as measured by the number of words

As figure 1 shows, most statements were very short. However, if we consider the complete results, it could be interesting to observe that most statements were either short noun phrases or brief imperative sentences designed to prompt possible customers into the buying habit. A further study of those types of statements appearing within the 20 ads analyzed would be relevant in order to observe how this type of advertisements were written.

First of all, we distinguished between noun phrases and sentences. The former totalled 461, equaling $57.05 \%$ of the total, of which most coincided with http linkers. We found 347 sentences within the 20 ads, of which 262 were simple sentences and 85 were compound sentences. Nevertheless, this type of sentences demanded further analysis as we hypothesize that a good number of these could be imperative sentences. Figure 2 shows the different verb tenses used within simple sentences with the corresponding predominance of imperative forms. 


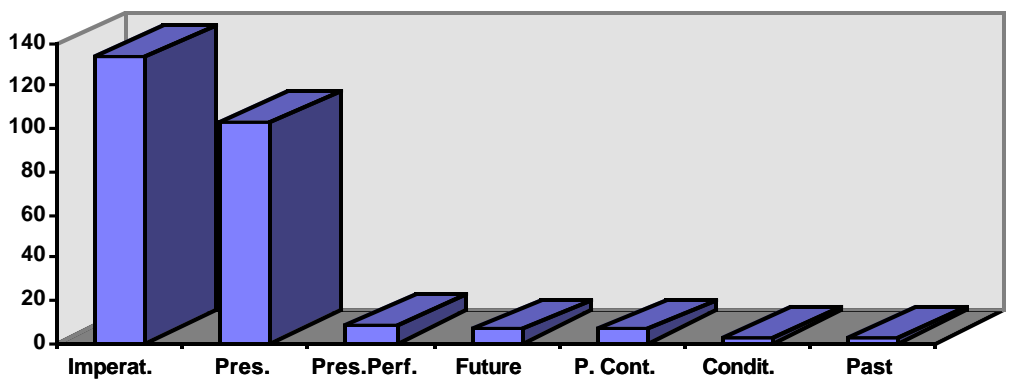

Figure 2. Use of verb tenses

As we can see in figure 2, most sentences appear either in the imperative (134) or in the simple present (103), amounting to a total of 90.45 per cent of the total number of verb tenses used.

An analysis of the 85 compound sentences observed provided 33 different combinations. Nevertheless, once again imperatives and simple present tenses were by far the most usual ones, appearing in 80 of those combinations. The most common compound sentence is the one following the simple present + simple present pattern (23 instances). In most cases, this pattern introduced either a conditional sentence (If you need further information, you can call...) or a judgment (This is an offer you can't refuse!). Additionally, in 15 of these 23 cases, at least one of the sentences appeared introduced by a modal verb.

Regarding the use of personal pronouns, as it could be expected in a set of texts where there is a predominance of imperative forms, you is the most frequently used personal pronoun, followed by it, and we/us (see table 1). You is used to systematically address the receiver of the advertisement, it is used as a substitute for the product being advertised, and we/us refer to the sellers. Additionally there are some instances of other pronouns such as they/them to refer to the competition, and I used to refer to the receiver of the advertisement in the context where he or she is required to give information about himself or herself. 


\begin{tabular}{|c|c|}
\hline $\begin{array}{l}\text { Type of personal } \\
\text { pronoun }\end{array}$ & Number of instances used \\
\hline$Y o u$ & 99 \\
\hline$I t$ & 18 \\
\hline$W e$ & 13 \\
\hline$I$ & 6 \\
\hline$U_{s}$ & 5 \\
\hline They & 3 \\
\hline Them & 2 \\
\hline She & 1 \\
\hline Her & 1 \\
\hline Yourself & 1 \\
\hline
\end{tabular}

Table 1. Use of personal pronouns

Observing all these data, we can conclude that most advertisements were short texts created by either simple sentences or noun phrases, giving special importance to imperative messages, prompting readers to buy the products advertised. Nevertheless, we also consider that this analysis should go further, paying special attention to the type of punctuation marks most often used when designing this type of text. With the exception of the traditional punctuation marks (period, comma, semi-colon), we observed that netvertising authors used different punctuation in order to transmit a message to potential customers. Table 2 shows our findings. 


\begin{tabular}{|c|c|c|c|}
\hline $\begin{array}{l}\text { Type of } \\
\text { punctuation } \\
\text { mark } \\
\end{array}$ & $\begin{array}{l}\text { Number of } \\
\text { instances } \\
\text { used }\end{array}$ & Purpose & Examples \\
\hline- & 15 & \begin{tabular}{|l} 
To introduce authors' \\
observations
\end{tabular} & \begin{tabular}{|l} 
Internet, intranet, extranet --we \\
make the net a business tool. \\
\end{tabular} \\
\hline$:$ & 27 & To offer examples & $\begin{array}{l}\text { Read all about it: full details on } \\
\text { AlphaServer Systems and the world- } \\
\text { class customers who use them to } \\
\text { work faster, smarter, better. }\end{array}$ \\
\hline( & 30 & $\begin{array}{l}\text { To offer examples and clarifying } \\
\text { instructions }\end{array}$ & \begin{tabular}{|l} 
(Click here for terms and price \\
details)
\end{tabular} \\
\hline 1 & 10 & \begin{tabular}{|l|} 
To offer options \\
\end{tabular} & Make a purchase/lease request. \\
\hline$!$ & 63 & $\begin{array}{l}\text { To stress the importance of an } \\
\text { offer }\end{array}$ & No fees or clubs to join! \\
\hline$?$ & 23 & Rhetorical questions & $\begin{array}{l}\text { Looking for high quality, low cost } \\
\text { auto insurance? }\end{array}$ \\
\hline$\cdots$ & 25 & $\begin{array}{l}\text { To introduce special offer or } \\
\text { funny comment }\end{array}$ & $\begin{array}{l}\text { Now it is possible to check out your } \\
\text { blind date... before the date. }\end{array}$ \\
\hline “” & 13 & $\begin{array}{l}\text { To introduce specific terms, } \\
\text { reported sentences, or newly- } \\
\text { coined terms }\end{array}$ & $\begin{array}{l}\text { It brings thousands of the hottest } \\
\text { uncensored videos out of the video } \\
\text { store "back room" and onto your } \\
\text { computer screen. }\end{array}$ \\
\hline I & 13 & To introduce foot linkers & $\begin{array}{l}\text { [What's new] [Tips and Time } \\
\text { Savers] }\end{array}$ \\
\hline
\end{tabular}

Table 2. Use of punctuation marks

As table 2 shows, advertising on the net clearly relies on a vast usage of different punctuation marks for distinct specific purposes.

\subsection{Content units: images and HT linkers}

Nevertheless, as in most other advertising genres, text is only one of the multiple features that linguists should study. For instance, a complementary analysis of the images appearing in the 20 ads selected for our research provided additional information for a better understanding of what each text was about. 5 To be precise, we have found three different types of images: pictures, cartoons and photographs.

After analyzing our corpus of ads, we observed a total number of 90 images. This number can be quite misleading, because they were not evenly distributed over the ads: whereas 2 ads had 12 images each, there were 5 ads with only 1 image. Table 3 shows the overall results.

5 We have also stressed the relevance of visual information in previous studies about other different genres, especially in the relationship between graphics and texts in research articles (Fortanet et al. 1996), and textbooks (Posteguillo 1997). 


\begin{tabular}{|c|c|}
\hline Number of images per text. & Instances observed \\
\hline 1 & 5 \\
\hline 2 & 3 \\
\hline 3 & 4 \\
\hline 4 & 1 \\
\hline 5 & 1 \\
\hline 6 & 1 \\
\hline 7 & 1 \\
\hline 10 & 1 \\
\hline 11 & 1 \\
\hline 12 & 2 \\
\hline Total & 20 \\
\hline
\end{tabular}

Table 3. Number of images used

Although results did not show a common trend in usage, all the advertisements analyzed used images in at least one instance, showing the importance of graphical information in advertising.

We also paid attention to the kind of images appearing within the ads analyzed. Our results showed, as we said above, that there were three important types of images: pictures, cartoons and photographs. A further analysis revealed that pictures were the most often used type of image, with cartoons and photographs far behind (see figure 3 below).
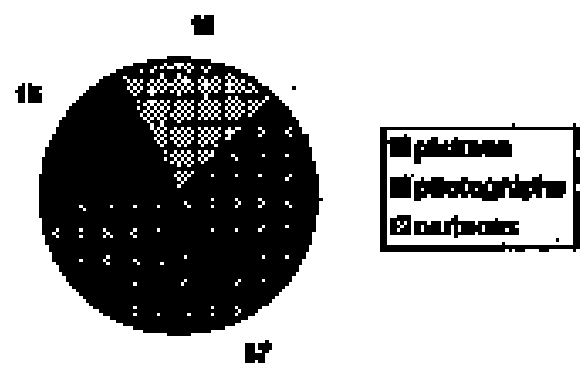

Figure 3. Different types of images

Additionally, we have observed that images are often interconnected with texts (in 56 instances out of 90, i.e., 62.2\%). This seemed to show 
that publicists frequently resort to images as a means of conveying their messages but that, at the same time, they decide to combine image with text, so that this combination becomes a characteristic of this genre

\begin{tabular}{|l|c|}
\hline \multicolumn{1}{|c|}{ Type of picture/text combination } & Number of instances used \\
\hline Picture only & 22 \\
\hline Picture + one text & 33 \\
\hline Picture + more than one text & 2 \\
\hline Photograph only & 5 \\
\hline Photograph + one text & 8 \\
\hline Photograph + more than one text & 2 \\
\hline Cartoon & 7 \\
\hline Cartoon + one text & 11 \\
\hline
\end{tabular}

Table 4. Type of picture/text combinations

What is most important is to observe how hypertext plays an important part within this genre. In order to analyze this hypothesis we considered the number of http linkers appearing within these ads, creating our own taxonomy to define them. Table 5 shows how most linkers were side-linking devices, offering the option to access a new web page from a clearly defined position on the screen:

\begin{tabular}{|l|c|}
\hline Type of http linker & Number of instances \\
\hline side linkers & 194 \\
\hline text-integrated linkers & 96 \\
\hline linkers within an image & 62 \\
\hline images as linkers & 53 \\
\hline foot linkers & 51 \\
\hline Total number of instances & 456 \\
\hline
\end{tabular}

Table 5. Type of http linkers

These results seem to indicate that a good number of linkers appear on the side of the page, either in bold type or with a different color, making quite explicit its web-page linking function. On the other hand, an average of 22.8 linkers per advertisement gives an idea of the neverending progression of the overall world of netvertising, and the huge commercial possibilities of this still underdeveloped genre. 


\section{Conclusion}

Most of these net advertisements are short texts, very much in line with other similar, more traditional forms of advertising. The conciseness regarding the form of expression to convey the message of the publicists is especially noticeable when it comes to syntax: a majority of statements are either very brief (made up of 1, 2, 3 or 4 words) or noun phrases. There is a corresponding predominance of imperatives and simple present tense verb form, most appropriate for this predominantly concise style.

This reduction of text length is offset by a wider use of other devices, namely punctuation marks, images, and http linkers. In our view, the incorporation of these additional elements aims at increasing the vividness of the advertisements. Certainly, the combination of the various types of images used (pictures, photographs, and cartoons) with the http linkers results in a more appealing message than if they were text-based advertisements.

We have carried out an initial analysis and categorization of http linkers; however, since these represent a specific feature of internet HT discourse, and are a novelty for the genre analyst, it is our contention that further research in this area should be carried out, not only from a purely linguistic point of view, but especially from a sociolinguistic or pragmatic perspective, in order to analyze which elements are selected by HT authors as linkers.

We believe in the increasing relevance of linguistic analyses of Internet genres for pedagogical purposes in English Language Teaching in general and, more specifically, in the contexts of English for Academic Purposes and English for Specific Purposes. Therefore, the introduction of the study of HT genres within the syllabus of applied linguistics courses within English Studies or English Philology degrees should be taken into consideration. ${ }^{6}$

6 We have already argued for a shift in English Philology degrees from a literary or theoretical linguistics-based emphasis towards a more applied linguistics/teacher training-based syllabus (Palmer and Posteguillo 1997b). 


\section{References}

Adell, J. (1994). World wide web: Un sistema hipermedia distribuido para la docencia universitaria. In F. Blázquez, J. Cabero, and F. Loscertales (eds), Nuevas Tecnologías de la Información y la Communicación para la Educación. Sevilla: Ediciones Alfar, 114-121.

Adell, J. (1996). Internet en educación: una gran oportunidad. In Net Conexión 11, 4447.

Bakhtin, M. (1986). Speech genres and other late essays (V.W. McGee, Trans.; C. Emerson and M. Holquist eds.). Austin: University of Texas Press.

Ben-Amos, D. (1976). Introduction. In D. Ben-Amos (ed), Folklore genres, ix-xv. Austin: University of Texas Press.

Berke, C. (1996). Successful advertising for small businesses. New York: Wiley.

Berkenkotter, C. and Huckin T.N. (1995). Genre knowledge in disciplinary communication. Hillsdale, NJ: Lawrence Erlbaum Associates.

Bhatia, V.K. (1993). Analysing genre: language use in professional settings. London: Longman.

Bhatia, V.K. (1994). Generic integrity in ESP. In R. Khoo (ed), LSP: problems and prospects. Singapore: Sherson Publishing House.

Bitzer, L. (1968). The rhetorical situation. In Philosophy and Rhetoric, 1: 1-14.

Chatterjee, P. (1996). Modeling consumer network navigation in World Wide Web sites: Implications for advertising. Dissertation proposal, Owen Graduate School of Management, Vanderbilt University. As it appears in Novak and Hoffman (1996).

Couture, B. (1986). Functional approaches to writing: research perspectives. Norwood: NJ: Ablex.

Devitt, A. (1993). Generalizing about genre: New conceptions of an old concept. In College Composition and communication, 44 /4: 573-586.

Ellsworth, J.H. and Ellsworth, M.V. (1997). Marketing on the Internet. New York: Wiley.

Ferrara, K. Brunner, H. and Whittemore, G. (1991). Interactive written discourse as an emergent register. In Written Communication, 8 (1): 8-34.

Fortanet, I., Palmer, J.C. and Posteguillo, S. (1996). Visual aids in English research articles. Paper read at the XIV symposium of the Spanish association of Applied Linguistics, Universitat Rovira i Virgili, Tarragona (Spain).

Fortanet, I., Posteguillo, S., Palmer, J.C. and Coll, J.F. (1996). Cross-disciplinary differences in abstracts. In S. Barrueco, E. Hernández and L. Sierra (eds), Lenguas para Fines Específicos, V: Investigación y Enseñanza. Alcalá de Henares: Publicaciones de la Universidad de Alcalá. Pp. 49-59.

Fortanet, I., Posteguillo, S., Palmer, J.C. and Coll, J.F. (1996). The writing of titles in academic research articles, VII Congreso Luso Hispano de Lenguas Aplicadas a las Ciencias, Badajoz: Universidad de Extremadura. 
Frow, J. (1980). Discourse genres. In The Journal of Literary Semantics, 9: 73-9.

Levinson, S.C. (1979). Activity types and language. In Linguistics, 17: 356-99.

Miller, C.R. (1984). Genre as social action. In Quarterly Journal of Speech, 70, 151167.

Myers, G. (1994). Words in ads. London: Edward Arnold.

Novak, T.P. and Hoffman, D.L. (1996). New metrics for new media: Toward the development of web measurement standards. http document: http://www 2000.ogsm. vanderbilt.edu/novak/web.standards/webstand.html

Palmer, J.C. and Posteguillo, S. (1997a). Layers of specificity in business english discourse. In J. Piqué and D.J. Viera (eds.), Applied languages: theory and practice in ESP. València: La Nau. Pp. 107-117.

Palmer, J.C. and Posteguillo, S. (1997b). A teacher trainig approach to a degree in English philology: Implementing TESP. In R. Howard and G. Brown (eds), Teacher education for LSP. Clevendon (U.K.): Multilingual Matters. Pp. 202-209.

Posteguillo, S. (1996). A genre-based approach to the teaching of reading and writing abstracts in computer science. In J. Piqué, J.V. Andreu-Besó, and D.J. Viera (eds.), English in Specific Settings. Valencia: Nau Llibres. Pp. 47-58.

Posteguillo, S. (1997). The use of graphical information in computer science textbooks. VI Congreso Luso-Hispano de Lenguas Aplicadas a las Ciencias. Viseu: Universidad Politécnica da Viseu.

Schutz, A. and T. Luckmann (1973). The structures of the life-world (R.M. Zaner and H.T. Engelhardt, Jr. Trans.). Evanston, IL: Northwestern University Press.

Swales, J.M. (1990). Genre analysis: English in academic and research settings, Cambridge: Cambridge University Press.

Ventola, E. (1984). Orientation to social semiotics in foreign language teaching. In Applied Linguistics, 5: 242-58.

Vestergaard, T. and Schröder, K. (1985). The language of advertising. Oxford: Blackwell.

Yates, J.A. and Orlikowski, W.J. (1992). Genres of organizational communication: A Structural approach. In Academy of Management Review, 17: 299-326.

\section{Corpus analysed}

http://www.novell.com/ROCKTHENET

http://www.ads.digital.com/world/

http://www.autobytel.com/

http://www.autotown.com/autoquote.html

http://www.prograde.com/nails/

http://www.clothesline.com/

http://micro.sitespecific.com/Quicken/TurboTax/cgi-bin/tt.iv.09.tt.x.ncgi/ 
http://www.att.com/w3403/attworldnetservice/needforspeedc.html http://www.intel.com/proshare/videophone/

http://www.buick.com/cgi-bin/homepage.pl ?buick+homepage+Y+ http://www.biztravel.com/V4/a20_a-0-0-0-

...age $=00000000 \&$ data $=0 \&$ target $=$ Main $\&$ dest $=$ here

http://www.sun.co

http://www.metlife.com/

http://members.aol.com/ucbooks/BG.index.html

http://www.securetax.com/

http://www.homearts.com/cgi-

bin/metascipt.pl...e/05brazilf.1.htm\%20/mktbanner/mbrazil.gif

http://www.register.com/nutek

http://www.globetrotter.com/

http://www.easports.com/fifa97/index.html

http://www.hardchannels.com/ 
